\title{
BMJ Open Identification and management of frail patients in English primary care: an analysis of the General Medical Services 2018/2019 contract dataset
}

\author{
Khulud Alharbi (D) , ${ }^{1}$ Thomas Blakeman, ${ }^{1}$ Harm van Marwijk (D) , \\ David Reeves (1) 1,3
}

To cite: Alharbi K,

Blakeman T, van Marwijk H, et al. Identification and management of frail patients in English primary care: an analysis of the General Medical Services 2018/2019 contract dataset. BMJ Open 2021;11:e041091. doi:10.1136/ bmjopen-2020-041091

- Prepublication history and additional supplemental material for this paper are available online. To view these files, please visit the journal online (http://dx.doi.org/10.1136/ bmjopen-2020-041091).

Received 01 June 2020 Accepted 15 July 2021

Check for updates

(c) Author(s) (or their employer(s)) 2021. Re-use permitted under CC BY-NC. No commercial re-use. See rights and permissions. Published by BMJ.

${ }^{1}$ National Institute for Health Research School for Primary Care Research, School of Health Sciences, University of Manchester, Manchester, UK ${ }^{2}$ Division of Primary Care and Public Health, Brighton and Sussex Medical School, University of Brighton, Brighton, UK

${ }^{3}$ Centre for Biostatistics, School of Health Sciences, University of Manchester, Manchester, UK

Correspondence to Dr Khulud Alharbi; khulud.alharbi@postgrad. manchester.ac.uk

\section{ABSTRACT}

Objectives The aim of this study was to explore the extent of implementation of the General Medical Services 2018/2019 'frailty identification and management' contract in general practitioner (GP) practices in England, and link implementation outcomes to a range of practice and Clinical Commissioning Group (CCG) factors.

Design A cross-sectional study design using publicly available datasets relating to the year 2018 for all GP practices in England.

Settings English general practices.

Data The analysis was conducted across 6632 practices in 193 CCGs with 9995558 patients aged 65 years or older.

Outcomes Frailty assessment rates, frailty coding rates and frailty prevalence rates, plus rates of medication reviews, falls assessments and enriched Summary Care Records (SCRs).

Analysis Summary statistics were calculated and multilevel negative binomial regression analysis was used to investigate relationships of the six outcomes with explanatory factors.

Results $14.3 \%$ of people aged 65 years or older were assessed for frailty, with $35.4 \%$ of these-totalling $5 \%$ of the eligible population — coded moderately or severely frail. $59.2 \%$ received a medications review, but rates of falls assessments (3.7\%) and enriched SCRs (21\%) were low. However, percentages varied widely across practices and CCGs. Practice differences in contract implementation were most strongly accounted for by their grouping within CCGs, with weaker but still important associations with some practice and CCG factors, particularly healthcare demand-related factors of chronic caseload and (negatively) \% of patients aged 65 years or older. Conclusion CCG appears the strongest determinant of practice engagement with the frailty contract, and fuller implementation may depend on greater engagement of CCGs themselves, particularly in commissioning suitable interventions. Practices understandably targeted frailty assessments at patients more likely to be found severely frail, resulting in probable underidentification of moderately frail individuals who might benefit most from early interventions. Frailty prevalence estimates based on the contract data may not reflect actual rates.
Strengths and limitations of this study

- To our knowledge, this is the first peer-reviewed study to evaluate the implementation of the General Medical Services (GMS) contractual requirements around patient frailty.

- The analysis was based on 2018 data for almost 10 million patients at more than 6000 general practitioner practices across all 193 Clinical Commissioning Groups (CCGs).

- Advanced methods of analysis and a broad range of potentially explanatory practice-level and CCG-level factors were investigated.

- It is possible that we lacked some key explanatory variables, though we analysed commonly used indicators of primary care demand and supply.

- The GMS contract data relating to practice activity around frailty are of unknown quality and consistency.

\section{INTRODUCTION}

Frailty is a dynamic and multidimensional state of increased vulnerability that often remains unspecified in primary care until a relatively minor event causes a significant health crisis $^{1}$ resulting in loss of independence. ${ }^{2}$ Frailty in the English population aged over 60 years was recently estimated at $14 \%$, rising to $65 \%$ of those aged 90 years and over. $^{3}$ Frail elderly individuals are at higher risk of adverse health outcomes such as falls, disability, hospitalisation and mortality. ${ }^{4}$ Emergent evidence suggests that appropriate interventions can potentially reverse frailty and its consequences, allowing people to stay at home for longer. ${ }^{56}$ This motivated changes to the 2017/2018 General Medical Services (GMS) contract for general practitioners (GPs) in England. ${ }^{7}$

The GMS contractual changes require GPs to identify frail patients and code them using 'an appropriate tool' ${ }^{7}$ coupled with a direct clinical validation of the level of frailty. For 
patients with moderate or severe frailty, general practices are then required to conduct a medication review, carry out a falls assessment if clinically indicated (introduced in 2018/2019), and where possible obtain consent to activate an enriched electronic Summary Care Record (SCR), which is automatically updated from the clinical record. Clinicians in other areas of the health and care system involved in the patient's direct care can see and use the SCR. ${ }^{8}$ Collecting and analysing data on frailty prevalence and management could help policymakers to better plan care. ${ }^{8}$

GP practices are grouped into local Clinical Commissioning Groups (CCGs). CCGs were established under the Health and Social Care Act 2013 and replaced primary care trusts. The aim was to shift commissioning responsibilities from central National Health Service (NHS) England to the local CCGs ${ }^{910}$ so as to shape services to meet local needs. CCGs now control around two-thirds of the NHS budget and influence the activities of the practices of which they are composed, potentially including how they respond to implementing contractual requirements. ${ }^{910}$

The identification and management of frailty within the GMS contract replaced the 'avoiding unplanned admissions' enhanced service specification. ${ }^{11}$ However, GPs have historically not coded 'frailty'; and may do so inconsistently. ${ }^{12}$ As such, implementing these changes may also be a challenge for primary care. ${ }^{13}$ The current study aimed to explore the extent of implementation of the frailty elements of the GMS contract in England and the variation in relation to a range of practice and CCG factors.

\section{METHODS}

\section{Study design and sample}

We used a cross-sectional study design that sourced multiple publicly available datasets relating to the financial year starting on 1 April 2018 for all GP practices in England.

\section{Patients and public involvement}

No patients or public were involved in this study.

\section{The GMS contract dataset}

Under the revised GMS contract, GP practice-based frailty assessments are an annual requirement, with data reported back to the NHS on an accumulative quarterly basis. Practices are expected to re-evaluate all patients 65 years and over for frailty annually and reclassify where appropriate. Our analysis focused on the full data for financial year 2018-2019. ${ }^{14}$ The list of relevant frailtyrelated measures is summarised in online supplemental table S1. All measures are simple patient counts for each individual practice, such as the number of patients aged 65 years or over assessed for frailty "using the appropriate tool'. No individual patient data are captured.
Outcome measures of identification and management of frailty

Using the raw contract data, we constructed six outcomes assessing different aspects of the frailty-related activity at each GP practice (online supplemental table S2). These outcomes addressed two key aspects of frailty activity: frailty identification and frailty management. Three outcomes concerned frailty identification: first, the frailty assessment rate represents the percentage of patients assessed for frailty out of the eligible practice population (ie, those aged 65 years or over). Second, the frailty coding rate is the percentage coded as moderately or severely frail out of those assessed. Finally, the frailty prevalence rate is the percentage coded moderately or severely frail out of the eligible population. We also report separate rates for the moderately frail and severely frail subgroups.

The remaining outcomes evaluated frailty management against three key interventions specified in the contractual requirements for GPs: first, the percentage of severely frail patients who received a medication review. Second, the percentage of moderately or severely frail who received a falls assessment. Finally, the percentage of moderately or severely frail consenting to the activation of an enriched SCR. Falls assessment data are collected as two counts: the number referred to a 'falls clinic' and the number having a 'falls discussion'. Only $5 \%$ of practices reported any falls discussions, but occasionally the sum across both exceeded the total number of frail patients, implying inclusion in both counts: therefore for an overall measure, we took the highest of the two counts at each practice.

\section{Practice and CCG characteristics}

Information on the characteristics of each individual GP practice and CCG was collected from a variety of publicly available online sources. We grouped these potential explanatory factors into three types: descriptive factors; healthcare capacity factors and healthcare demand factors. Brief descriptions follow; full details of each explanatory factor and the relevant source appear in online supplemental table S3.

Descriptive factors of practices were: list size; contract type (GMS, Personal Medical Services (PMS) or Alternative Provider Medical Services (APMS)); overall Quality and Outcomes Framework (QOF) score for 2018-201915; \% of GPs who qualified in the UK; \% of GPs under 35 years; $\%$ of GPs over 50 years and \% of GPs who were female. Descriptive CCG factors were: total population size.

Healthcare capacity factors of practices were: number of fulltime equivalent (FTE) GPs; number of FTE nurses (each expressed as a rate per 10000 patients); the availability of a pharmacist in the practice. CCG capacity factors were: CCG total nurses per 10000 registered patients and CCG total GPs per 10000 registered patients.

Healthcare demand factors of practices were: local area rurality (urban major conurbation, urban city or town, rural town, rural village); Index of Multiple Deprivation (IMD) 2015 (in national quintiles); \% of registered 
patients aged 65 years or over; $\%$ of patients from black and minority ethnic groups (BME); chronic caseload (mean number of QOF chronic conditions per registered patient). CCG demand factors were: population mean IMD quintile; rurality (predominantly rural, predominantly urban, urban with significant rural); chronic caseload; \% population BME and $\%$ population aged 65 years or over. Healthcare region was an additional explanatory factor.

IMD is a UK government-generated measure of local area deprivation, constructed as a weighted mean of seven distinct domains of deprivation; income, employment, education, skills and training, health and disability, crime, barriers to housing and services and living environment. ${ }^{16}$

Factors measured on numerical or percentage scales were categorised into three, four or five reasonably sized groups, rather than treated as continuous measures, since the very large sample size allowed this. Examination of the data suggested that many relationships to outcomes were non-linear and categorised measures avoid assuming linearity; this also facilitated presentation of results as subgroup ('marginal') means for easier interpretation. Table 1 summarises the practice-level factors. The CCGlevel factors are summarised in online supplemental table S4.

\section{Statistical analysis}

We conducted descriptive analysis for all six frailty outcomes at the practice, CCG and national (all-England) levels, using the full cohort of 6632 practices with patients aged 65 years or over in the contract dataset. The usable practice sample varied by outcome: practices that conducted no frailty assessments did not contribute to analyses of outcomes for patients assessed for frailty; and practices that coded no patients as frail did not contribute to analysis of outcomes for patients coded as frail.

Multilevel negative binomial regression (NBR) was used to investigate relationships between the six frailty outcomes and practice-level and CCG-level explanatory factors. The dependent variable was the raw numerator for the outcome (eg, number of patients assessed) and the exposure variable the raw denominator (eg, number eligible for assessment), at each practice. Dispersion was assumed proportional to each practice denominator and robust estimates of variance, making no distributional assumptions and allowing for correlations between practices within CCGs, used to account for any differences away from a true negative binomial distribution. ${ }^{17}$ Online supplemental figure S1 and S2 depict the distributions of the practice numerators for each outcome measure broken down by practice list size; all outcomes were highly right-skewed with a long tail, as is typical for a negative binomial distribution. NBR analysis was undertaken in a two-stage process. At stage 1, we performed univariate regressions against each practice-level and CCG-level explanatory factor (plus healthcare region) separately and identified those with an association with the outcome at $\mathrm{p} \leq 0.1$ - a high $\mathrm{p}$ value was used to avoid prematurely rejecting potentially important relationships. At stage 2, all identified factors were used together in a multilevel multivariate backwards stepwise NBR removing variables not significant at $\mathrm{p} \leq 0.05$.

To facilitate interpretation, results are reported in the form of marginal (subgroup) means adjusted for all other factors in each model. Each marginal mean represents the adjusted mean incidence rate across practices in the subgroup.

Missing or unreliable data resulted in a slightly reduced sample for NBR analyses. Ninety-eight (98) practices with a reported list size that differed by more than $20 \%$ between the contract dataset and the workforce dataset were excluded due to concerns that their workforce data may be out of date or unreliable for other reasons. These practices tended to be very small (mean patient list size 2595). Some practices lacked information on certain explanatory variables: the largest number being 270 $(4.3 \%)$ missing data on GP place of qualification, age and gender (online supplemental table S3). The maximum NBR analysis sample was 6534 practices, though as with the descriptive analysis the usable sample varied by outcome. Some practices conducted no frailty assessments and to assess robustness against this, we repeated the NBR excluding these from relevant analyses.

To assess the degree to which practice-level and CCG-level factors along with mean differences between CCGs explained the variation in the frailty outcomes, we used the method proposed by Zheng and Agresti, ${ }^{18}$ of computing correlations between the observed and model-based predicted practice scores. We used the NBR models to obtain predicted outcome scores for each practice based on (1) the practice and CCG factors in the model, (2) the CCG 'Empirical Bayes' means, (3) factors plus CCG means. Empirical Bayes estimated the mean practice score in each CCG after removal of variation due to practice and CCG factors.

\section{RESULTS}

\section{National (all-England) level}

The 2018/2019 GMS contract dataset indicated a total population of patients eligible for frailty assessment across all 6632 GP practices in England, of 9995558 people aged 65 years or older. Of these, $1435322(14.3 \%)$ received an assessment for frailty, of which 326037 (22.7\% of those assessed) were subsequently coded as moderately frail and $183041(12.7 \%)$ as severely frail. This yields a prevalence rate in all patients aged 65 years or over of $5 \%$ with $3.2 \%$ and $1.8 \%$ moderately and severely frail, respectively. The incidence of frailty management outcomes were: $59.2 \%$ of severely frail patients received a medication review; $3.7 \%$ of moderately and severely frail patients received a falls assessment, and $21 \%$ gave consent to activate their enriched SCR (table 2).

\section{Practice and CCG levels}

Figure 1 and online supplemental figure S3 depict GP practice rates for each frailty outcome, with the $\%$ rate 
Table 1 Summary of practice factors

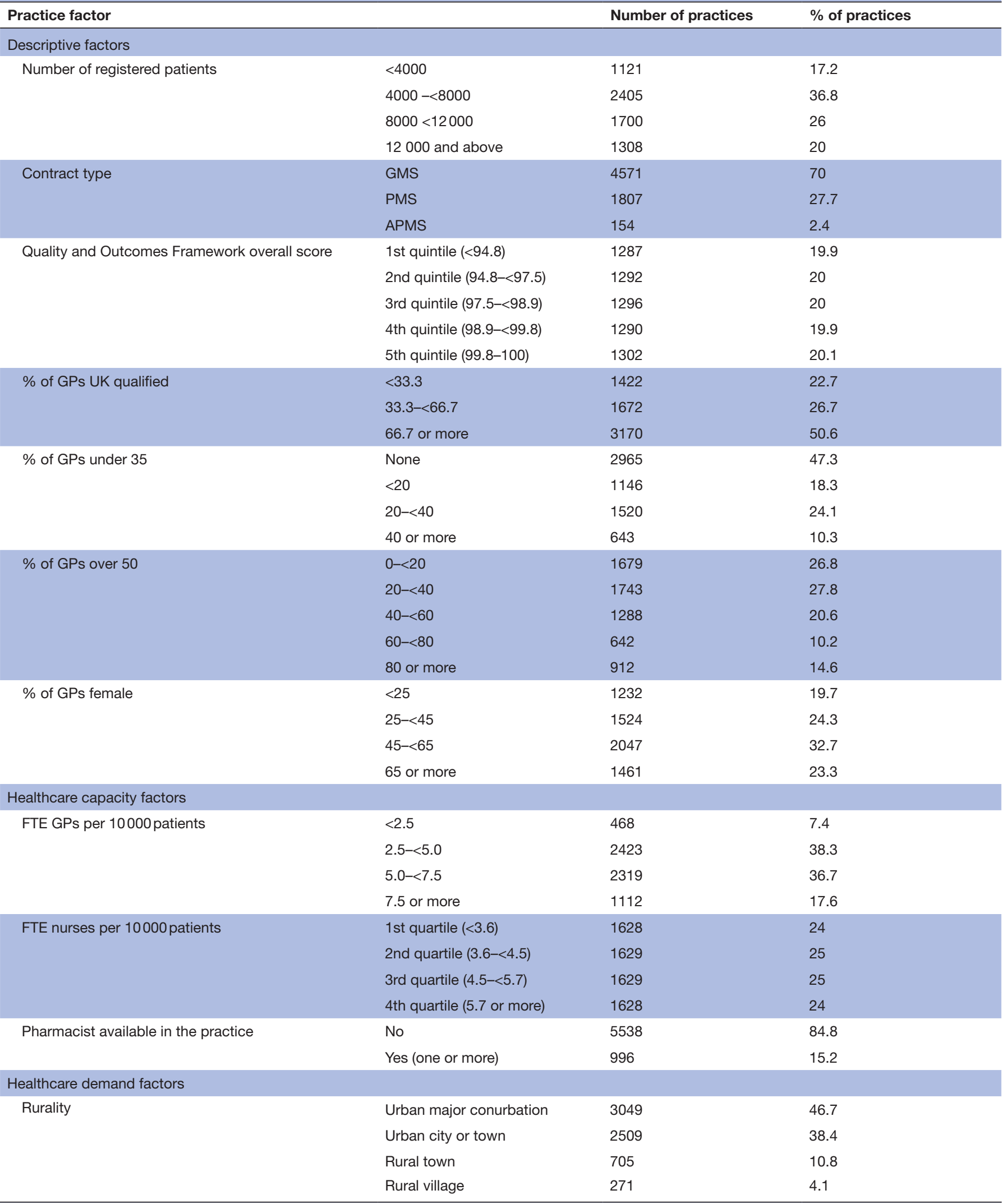

Continued 
Table 1 Continued

\begin{tabular}{|c|c|c|c|}
\hline Practice factor & & Number of practices & $\%$ of practices \\
\hline \multirow[t]{5}{*}{ Index of Multiple Deprivation } & $\begin{array}{l}\text { 1st national quintile (most } \\
\text { deprived) }\end{array}$ & 1858 & 28.4 \\
\hline & 2nd national quintile & 1503 & 23 \\
\hline & 3rd national quintile & 1230 & 18.8 \\
\hline & 4th national quintile & 1071 & 16.4 \\
\hline & $\begin{array}{l}\text { 5th national quintile (least } \\
\text { deprived) }\end{array}$ & 872 & 13.3 \\
\hline \multirow{4}{*}{$\%$ of patients $65+$} & $10-<15$ & 1287 & 19.7 \\
\hline & $15-<20$ & 1778 & 27.2 \\
\hline & $20-<25$ & 1479 & 22.6 \\
\hline & 25 or more & 902 & 13.8 \\
\hline$\%$ of BME in practice LSOA & 50 or more & 786 & 12 \\
\hline \multirow[t]{5}{*}{ Chronic caseload } & $<0.45$ & 861 & 13.3 \\
\hline & $0.45-<0.55$ & 1119 & 17.3 \\
\hline & $0.55-<0.65$ & 1676 & 25.9 \\
\hline & $0.65-<0.75$ & 1632 & 25.2 \\
\hline & 0.75 or more & 1179 & 18.2 \\
\hline
\end{tabular}

APMS, Alternative Provider Medical Services; BME, black and minority ethnic; FTE, full-time equivalent; GMS, General Medical Services; GPs, general practitioners; LSOA, Lower Layer Super Output Area; PMS, Personal Medical Services.

on the Y-axis and practices on the $\mathrm{X}$-axis in rank order of descending rate size. The sample was smaller than 6632 for some outcomes: the frailty coding rate only applied to practices that conducted frailty assessments $(n=6293)$; medication and SCR rates to practices with a non-zero count of moderate or severe patients $(n=5785)$; falls assessment rates to those with severe patients $(n=5264)$. For all outcomes, rates varied widely, from $0 \%$ up to-or close

\begin{tabular}{|c|c|c|c|}
\hline $\begin{array}{l}\text { Number of practices } \\
\text { contributing data* }\end{array}$ & $\begin{array}{l}\text { Total number of } \\
\text { patients }\end{array}$ & Population rate $†$ & $\begin{array}{l}\text { Mean GP } \\
\text { practice rate }\end{array}$ \\
\hline \multicolumn{4}{|c|}{ Frailty identification outcomes } \\
\hline 6632 & 1435322 & $14.3 \%$ & $15.5 \%$ \\
\hline 6293 & 509078 & $35.4 \%$ & $49.5 \%$ \\
\hline 6293 & 183041 & $12.7 \%$ & $22.5 \%$ \\
\hline 6632 & 509078 & $5.0 \%$ & $5.6 \%$ \\
\hline 6632 & 326037 & $3.2 \%$ & $3.6 \%$ \\
\hline 6632 & 183041 & $1.8 \%$ & $2.0 \%$ \\
\hline \multicolumn{4}{|c|}{ Frailty management outcomes } \\
\hline 5785 & 107026 & $21 \%$ & $23.8 \%$ \\
\hline
\end{tabular}

*Based on 6632 practices in the contract dataset. However, not all practices assessed patients for frailty, and some that did coded no patients as moderately/ severely frail, hence the practice sample was smaller for some outcomes.

†Rate in the combined population across all GP practices.

tWas referred to a 'falls clinic' and/or had a falls discussion.

GP, general practitioner; SCR, Summary Care Record. 


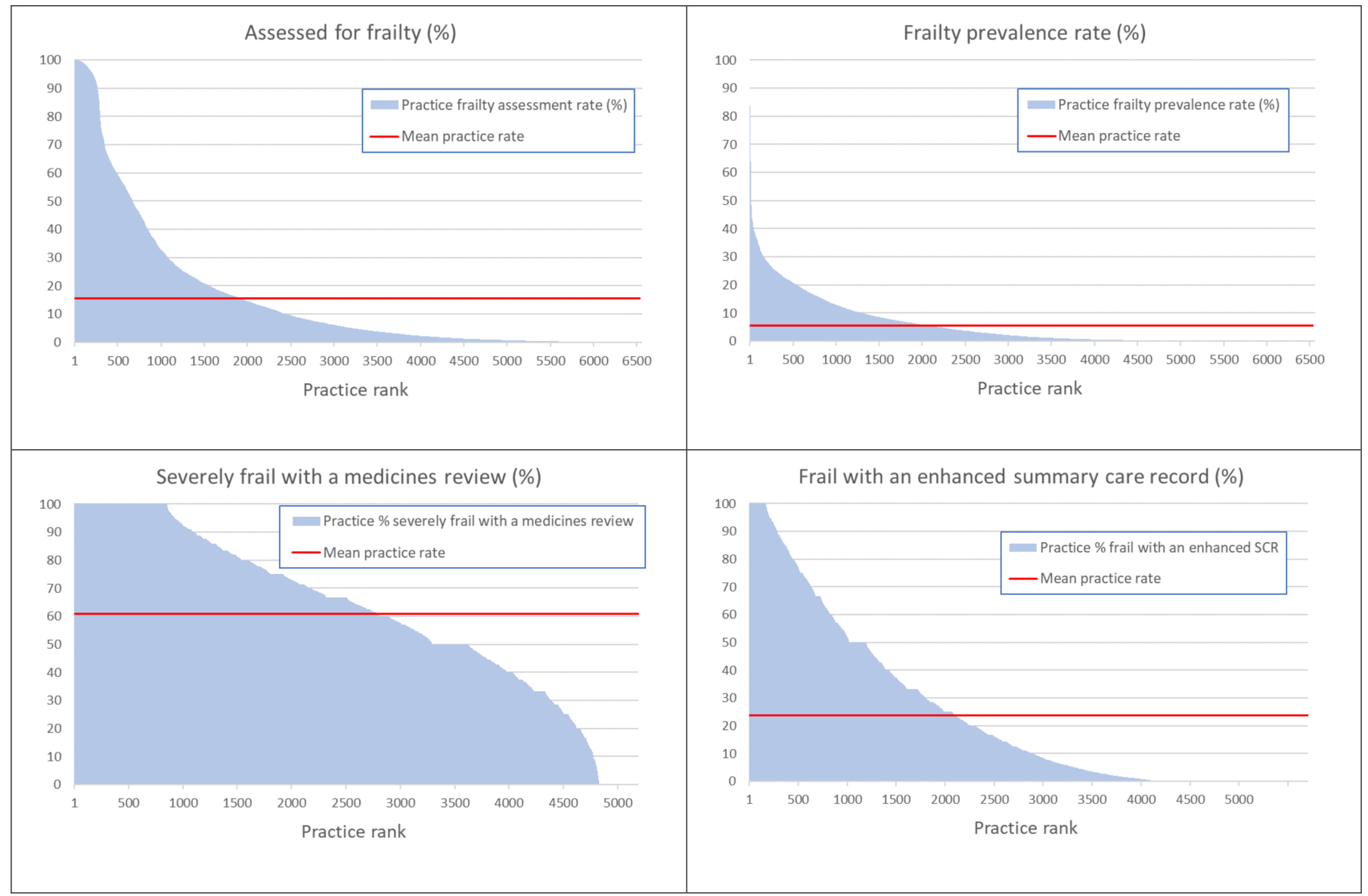

Figure 1 Frailty assessment and management outcomes by GP practice, in descending order of rate size. GP, general practitioner.

to- $100 \%$ and in most cases were highly skewed, with most practices scoring at the low end. Frailty assessment rates were below $5 \%$ for $50 \%$ of practices, but only 339 $(5.1 \%)$ reported zero assessments, indicating that $95 \%$ had engaged with the contract to at least some degree. Non-engaging practices were generally smaller (mean registered patients $=5584$ vs $8741 ; p<0.001$ ), though the group also included some of the very largest practices.

For most outcomes, the mean practice rate was similar to the population rate (table 2). However, a notable exception was the mean practice frailty coding rate of $49.6 \%$, compared with the population rate of $35.4 \%$. Inspection of the data revealed this to be due to the population rate being dominated by larger practices. It should be noted that the NBR method estimates associations with practicelevel rates and not with population rates.

CCG-level scores were derived by pooling the patients across all practices in each CCG. A large majority of practices in all CCGs engaged with the contract and all outcomes were derived for all CCGs (online supplemental figure S4). Variation between CCGs in contractrelated activity was very wide, with percentages assessed for frailty ranging from $0.5 \%$ to $69.4 \%$. Percentages coded moderately or severely frail ranged from $4.2 \%$ to $100 \%$, while prevalence rates ranged from $0.3 \%$ to $21.5 \%$.
CCG variation on the three frailty management outcomes was likewise very high.

\section{Frailty identification outcomes and their associations with practice and CCG factors}

Factors associated with frailty assessment rates

The number of people over 65 years of age assessed for frailty varied from $0 \%$ up to $100 \%$ by practice (figure 1 ). However, only $10 \%$ of practices had assessed more than $50 \%$ of their eligible patients. After univariate and multivariate analyses, relationships were found $(p<0.05)$ between frailty assessment and a number of practice and CCG factors (table 3 and figure 2).

\section{Practice factors}

Healthcare descriptive factors, higher assessment rates were associated with higher QOF scores $(\mathrm{p}=0.013)$. Practices in the lowest quintile of QOF scores had a mean assessment rate of $12.9 \%$, rising to $15.8 \%$ at the fourth quintile and levelling off there, perhaps related to differences in QOF scores between the top two quintiles being very small. The relationship to \% of UK-qualified GPs indicated a slightly raised rate at practices with $33.3 \%-<66.7 \%$ UK qualified $(\mathrm{p}=0.006)$ and assessment rates were also slightly higher at practices with $45 \%$ or more representation of female GPs $(\mathrm{p}=0.001)$. 
Table 3 Results from univariate and multivariate analyses of frailty assessment rates

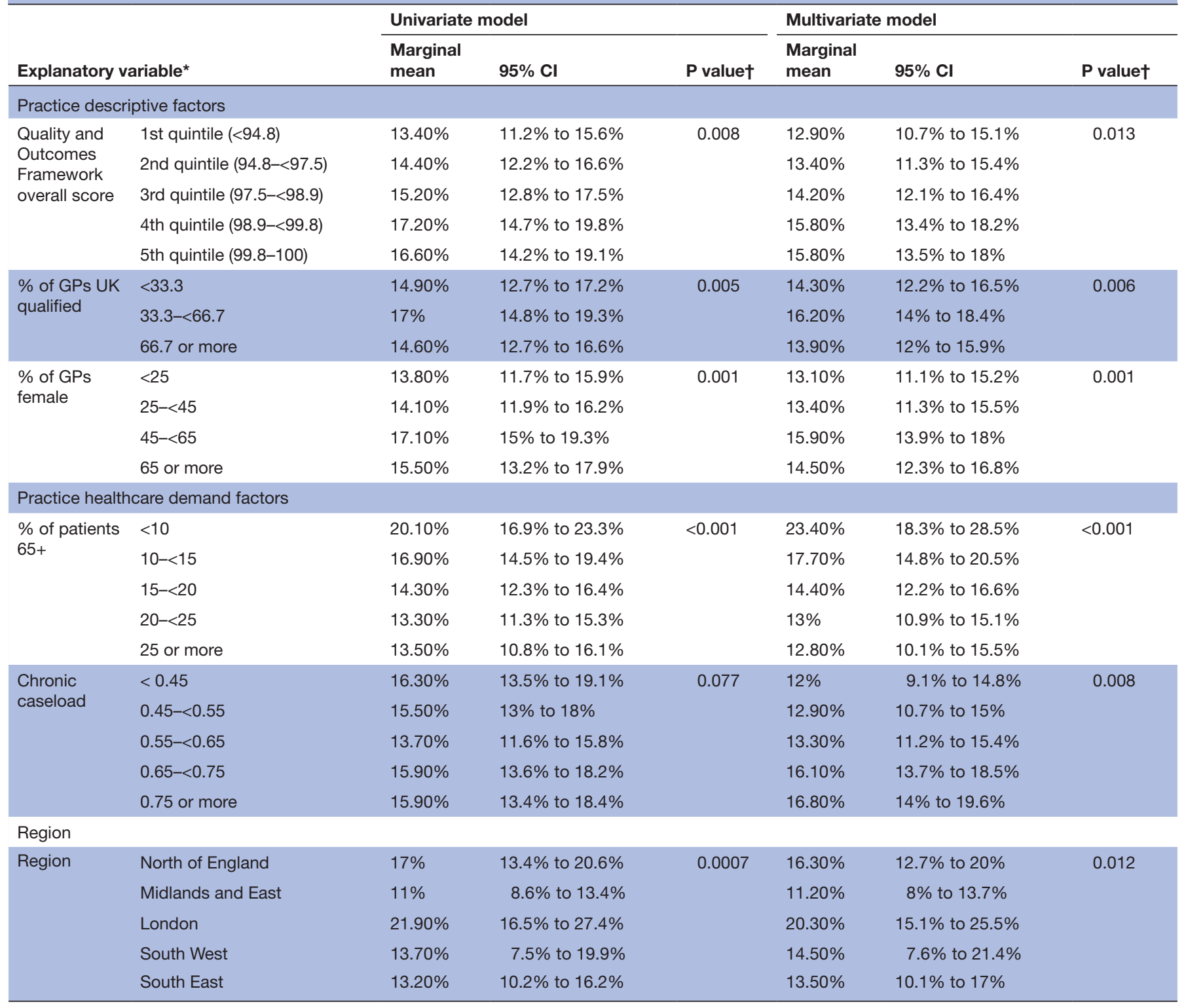

${ }^{*}$ Factors significantly associated with the outcome after multivariate backwards stepwise regression. †P value for overall comparison of marginal means across all levels of the factor. GPs, general practitioners.

Healthcare capacity factors showed no significant relationships to frailty assessment rates.

Healthcare demand factors, particularly notable was a negative curvilinear relationship between a larger older patient population and the percentage receiving a frailty assessment $(\mathrm{p}<0.001)$ : practices with less than $10 \%$ of patients aged $65+$ years had a mean assessment rate of $23.4 \%$, after which rates rapidly dropped until levelling off at $13 \%-14 \%$ for practices with more than $15 \%$ aged $65+$ years. Conversely, frailty assessment rates rose as chronic caseload increased $(\mathrm{p}=0.008)$, slowly at first but more so with a chronic caseload greater than 0.65: practices with the highest caseloads had a mean assessment rate of $16.8 \%$ compared with $12 \%$ for practices with the lowest caseloads.

\section{CCG factors}

No CCG-level factors were significantly related to frailty assessment rates. However, rates differed by health region $(\mathrm{p}=0.012)$, with the mean rate being highest in the London region $(20.3 \%)$, but almost half that level in the Midlands and East England (11.2\%).

After exclusion of practices that made no assessments, all results stayed essentially the same.

Factors associated with frailty coding rates

\section{Practice factors}

Descriptive factors with statistically significant associations with rates of frailty coding in those assessed were practice size and \% of UK-qualified GPs. Coding rates showed a curvilinear relationship to practice size $(\mathrm{p}<0.001)$, 


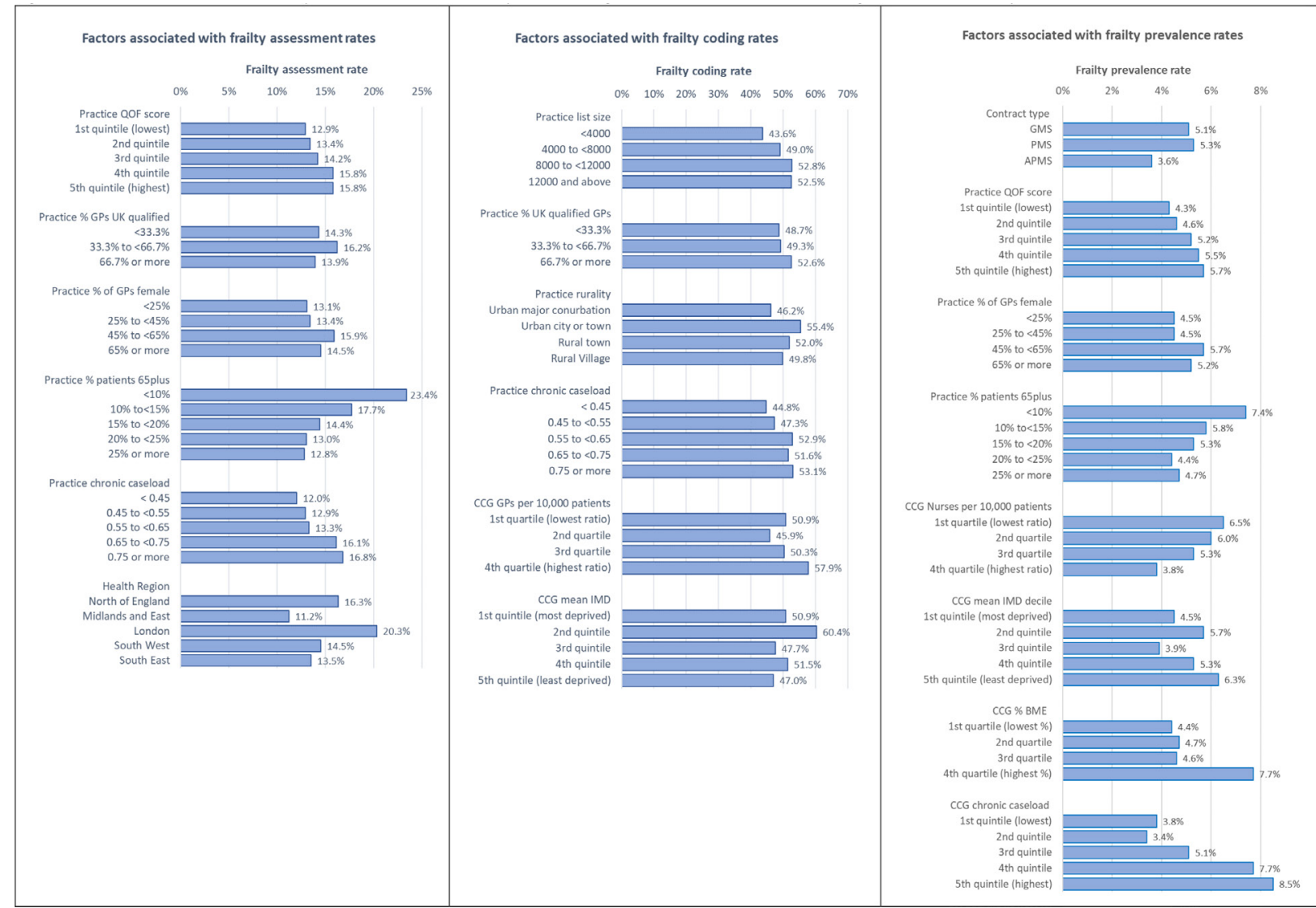

Figure 2 Factors associated with frailty identification outcomes $(p<0.05)$; marginal means from multivariate negative binomial analysis. APMS, Alternative Provider Medical Services; BME, black and minority ethnic; CCG, Clinical Commissioning Group; GMS, General Medical Services; GPs, general practitioners; IMD, Index of Multiple Deprivation; PMS, Personal Medical Services; QOF, Quality and Outcomes Framework.

increasing from a mean of $43.6 \%$ at the smallest practices $(<4000$ registered patients) then levelling off to $52.8 \%$ and $52.5 \%$ at large $(8000-<12000$ patients $)$ and very large (12000 and above). Frailty coding rates also increased slightly with a higher \% of UK-qualified GPs $(\mathrm{p}=0.002)$ (online supplemental table S5 and figure 2).

Healthcare demand factors, coding rates were highest in urban cities and towns (55.4\%) and lowest in urban major conurbations $(46.2 \%)$. Coding rates demonstrated a curvilinear increase with chronic caseload $(\mathrm{p}=0.011)$ : from $44.8 \%$ in practices with the lowest levels of chronic caseload, then levelling off at $52 \%-53 \%$ beyond a caseload score of 0.55 (online supplemental table S5 and figure 2).

\section{CCG factors}

Although significant, relationships to CCG GP staffing rates and IMD did not demonstrate a clear pattern (online supplemental table S5 and figure 2).

Factors associated with frailty prevalence rates

\section{Practice factors}

Descriptive factors, significant associations were found between frailty prevalence rates and contract type $(p=0.02)$, QOF scores $(p<0.001)$ and $\%$ of female GPs $(<0.001)$. Prevalence rates were lower at practices with
APMS contracts $(3.6 \%)$ compared with a GMS $(5.1 \%)$ or PMS contract $(5.3 \%)$. Prevalence rates increased in linear fashion as QOF scores increased, though by only small degrees, and were also slightly higher at practices with beyond $45 \%$ representation of female GPs (online supplemental table S6 and figure 2).

Healthcare demand factors, a significant negative curvilinear relationship to numbers of older patients was apparent $(\mathrm{p}<0.001)$, with prevalence decreasing from $7.4 \%$ at practices with $<10 \%$ patients $65+$ years, and levelling off at between $4 \%$ and $5 \%$ at practices with $20 \%$ or more $65+$ years (online supplemental table S6 and figure 2).

\section{CCG factors}

Healthcare capacity factors, prevalence rates were associated with one healthcare capacity factor, nurse staffing levels, but with rates being counterintuitively lower as the CCG nurse-to-patients ratio increased $(\mathrm{p}<0.019)$ (online supplemental table S6 and figure 2).

Healthcare demand factors, there were observable relationships with three CCG demand factors, IMD ( $\mathrm{p}=0.042), \%$ of BME $(p=0.040)$ and chronic caseload $(p<0.001)$. The relationship to IMD showed no clear pattern, and for $\%$ of BME was flat at 4\%-5\% except for CCGs in the upper 
Table 4 Results from univariate and multivariate analyses of medication review rates

\begin{tabular}{|c|c|c|c|c|c|c|c|}
\hline \multirow{2}{*}{\multicolumn{2}{|c|}{ Explanatory variable* }} & \multicolumn{3}{|l|}{ Univariate model } & \multicolumn{3}{|c|}{ Multivariate model } \\
\hline & & Marginal mean & $95 \% \mathrm{Cl}$ & $\mathrm{P}$ value $†$ & Marginal mean & $95 \% \mathrm{Cl}$ & $P$ value \\
\hline \multicolumn{8}{|c|}{ Practice descriptive factors } \\
\hline \multirow{2}{*}{$\begin{array}{l}\text { \% of GPs UK } \\
\text { qualified }\end{array}$} & $33.3 \%-<66.7$ & $59.6 \%$ & $57.7 \%$ to $61.5 \%$ & & $59.6 \%$ & $57.8 \%$ to $61.5 \%$ & \\
\hline & 66.7 or more & $61.5 \%$ & $60 \%$ to $63 \%$ & & $62.5 \%$ & $60 \%$ to $62.9 \%$ & \\
\hline \multirow{3}{*}{$\begin{array}{l}\text { FTE GPs per } \\
10000 \text { patients }\end{array}$} & $2.5-<5.0$ & $59.2 \%$ & $57.6 \%$ to $60.8 \%$ & & $59.5 \%$ & $57.9 \%$ to $61.1 \%$ & \\
\hline & $5.0-<7.5$ & $61.4 \%$ & $59.8 \%$ to $63 \%$ & & $61.4 \%$ & $59.8 \%$ to $62.9 \%$ & \\
\hline & 7.5 or more & $61.6 \%$ & $59.4 \%$ to $63.9 \%$ & & $61.5 \%$ & $59.2 \%$ to $63.8 \%$ & \\
\hline
\end{tabular}

*Factors significantly associated with the outcome after multivariate backwards stepwise regression.

$\dagger P$ value for overall comparison of marginal means across all levels of the factor.

FTE, full-time equivalent; GPs, general practitioners.

quartile of BME populations, at 7.7\%. The relationship to chronic caseload started flat at $3 \%-4 \%$ for the first two quintiles, then rose gradually to reach $8.5 \%$ in the upper quintile of chronic caseload (online supplemental table S6 and figure 2).

When practices making no assessments were excluded from the analysis, the CCG demand factors of IMD $(\mathrm{p}=0.077)$ and $\%$ of BME $(\mathrm{p}=0.069)$ ceased to reach statistical significance.

\section{Frailty management outcomes and their associations with practice and CCG factors \\ Factors associated with medication review rates \\ Practice factors}

Descriptive factors, rates of medication reviews in those coded as severely frail were associated with a larger percentage of UK-qualified GPs $(\mathrm{p}=0.038)$ but the effect was modest: the rate was quite flat at $59 \%-60 \%$ until the proportion of UK-qualified GPs reached two-thirds or more, when it rose to $62.5 \%$ (table 4 and online supplemental figure S5).

Healthcare capacity factors, rates of medication reviews showed a non-linear increase with practice ratio of FTE GPs to patients $(\mathrm{p}=0.030)$. The mean rate initially increased from $57.7 \%$ in practices with $<2.5$ FTE GPs per 10000 and then levelled off to around $61.5 \%$ at practices with a ratio of 5 or more (table 4 and online supplemental figure S5).

\section{CCG factors}

No significant relationships were detected to any CCGlevel factors, or to health regions (table 4 and online supplemental figure S5).

\section{Factors associated with falls assessment rates}

\section{Practice factors}

Healthcare demand factors, rates of severely and moderately frail patients receiving a falls assessment were associated with rurality $(p<0.010)$, with the rate slightly higher at practices located in urban cities and towns, $5.4 \%$, and lowest at 3.6\% for practices in rural villages (online supplemental figure S5 and online supplemental table S7).

\section{CCG factors}

Healthcare demand factors, fall assessment rates were highest at predominantly rural CCGs $(6.3 \%)$ and lowest at CCGs with an urban-rural mix (3.9\%) (online supplemental figure S5 and online supplemental table S7).

\section{Factors associated with enriched SCR rates \\ Practice factors}

Descriptive factors, enriched SCR rates demonstrated a relationship to number of registered patients $(p=0.030)$ but with no clear pattern. A relationship to QOF scores was apparent $(\mathrm{p}<0.001)$, rising gradually from a mean of $20.3 \%$ for practices in the lowest quintile of QOF scores to $27.6 \%$ at those in the fourth quintile and then stabilising, though QOF scores differed only fractionally between the top two quintiles (online supplemental figure S5 and online supplemental table S8).

Healthcare capacity factors, rates of enriched SCRs also varied with practice GP staffing levels $(\mathrm{p}=0.039)$, but by only small degrees (online supplemental figure S5 and online supplemental table S8).

\section{CCG factors}

Healthcare capacity factors, in the form of overall GP $(\mathrm{p}=0.031)$ and nurse $(\mathrm{p}=0.006)$ staffing levels, were also associated with SCR consent rates, with a modest increases at higher staffing levels (third and fourth quintiles) in both cases (online supplemental figure S5 and online supplemental table S8).

\section{Overall patterns of associations}

The large majority of explanatory factors demonstrated statistically significant associations with at most one or two of the six frailty outcomes (online supplemental table S9). The only exceptions were higher QOF scores, associated with higher frailty assessment and prevalence rates, 
Table 5 Correlations between observed and predicted frailty outcome scores

\begin{tabular}{llll}
\hline Outcome measure & Practice and CCG factors & CCG means† & Factors plus CCG meansł \\
\hline $\begin{array}{l}\text { Assessed for frailty } \\
\begin{array}{l}\text { Coded moderately or severely frail out of } \\
\text { those assessed }\end{array}\end{array}$ & 0.18 & 0.48 & 0.52 \\
$\begin{array}{l}\text { Coded moderately or severely frail out of } \\
\text { those eligible for assessment }\end{array}$ & 0.25 & 0.45 & 0.53 \\
$\begin{array}{l}\text { Severely frail receiving a medications } \\
\text { review }\end{array}$ & 0.05 & 0.41 & 0.49 \\
$\begin{array}{l}\text { Moderately or severely frail with a falls } \\
\text { assessment }\end{array}$ & 0.08 & 0.27 & 0.27 \\
$\begin{array}{l}\text { Moderately or severely frail with an } \\
\text { enriched SCR }\end{array}$ & 0.17 & 0.31 & 0.33 \\
\hline
\end{tabular}

*Practice and CCG factors from the stepwise negative binomial regression model. †CCG Empirical Bayes means only. ¥Practice and CCG factors plus CCG Empirical Bayes means. CCG, Clinical Commissioning Group; SCR, Summary Care Record.

and increased use of enriched SCRs; and proportion of UK-qualified GPs, associated with assessment and prevalence rates, and medication review rates.

\section{Relative contribution of explanatory factors and CCGs to outcomes variation}

Table 5 summarises the correlations between the observed and model-predicted outcome scores. Correlations with predicted scores based on practice and CCG factors only (ie, factors from the multivariate solution) were all low to modest, with a maximum of 0.28 for the frailty coding outcome. Correlations with CCG means alone were all notably higher and ranged from 0.27 to 0.48 . Correlations with predictions based on factors plus CCG means were slightly higher still and exceeded or were near to 0.5 for all three frailty identification outcomes.

\section{DISCUSSION}

\section{Statement of the principal findings}

Only around one in every six persons eligible for, and due, a frailty assessment under the GMS contract received one, with just over one-third assessed to be moderately or severely frail, meaning that overall $5 \%$ were coded as frail. Actual national rates of $12 \%$ for moderate and $3 \%$ for severe would be realistic estimates, ${ }^{19}$ practices thus identified $27 \%$ of the moderately frail population and $60 \%$ of those severely frail. Moderately frail people appear considerably underidentified. Regarding the contract frailty management requirements, rates of enriched SCRs and falls assessments were universally low, whereas most of the severely frail did receive a medication review.

There was wide variation in outcomes between both practices and CCGs. Relationships to practice and CCG factors were often low level but statistically significant due to the large practice sample. One strong association was the finding that frailty assessment rates differed between health regions by a factor of almost two. Other strong associations were negative relationships between practice proportions of older patients and frailty assessment and prevalence rates, and positive relationships between chronic caseloads (at practice or CCG level) and all frailty identification outcomes. All these relationships were curvilinear, mostly with outcome rates levelling off at higher levels of the explanatory factor. The finding that assessment rates were lower at practices with more older patients yet higher where the chronic caseload was greater implies targeting of those with greater chronicity/severity. It was also notable that frailty assessment rates showed no associations with any healthcare capacity factors, although did vary by region and less strongly by practice QOF scores. Although practice size was not associated with assessment rates, larger practices coded more assessed patients as frail.

Notwithstanding the above, for all outcomes the strongest determinant of practice performance was CCG membership. Most of the funding for primary care now flows through CCGs and as of April 2018 over $90 \%$ of CCGs had become fully responsible for the commissioning of GP services, ${ }^{20}$ making CCGs highly influential over primary care in their areas. Under NHS England's Improvement and Assessment Framework, CCG performance is assessed against a range of indicators, none of which relate to patient frailty. ${ }^{20}$ Thus, CCGs may have prioritised achieving the indicators they are judged on, with only a minority devoting time to developing and implementing policy and strategy to support the delivery of care to frail older patients. ${ }^{21}{ }^{22}$ In CCGs where a frailty policy was lacking or weak, wide practice variation was possibly driven by degree of individual practice interest in frailty as an approach to structuring care and in meeting the contractual requirements. However, evaluating these assertions would require further research, such as in-depth surveying of CCG staff and review of published policies, which is beyond the scope of the present study. 


\section{Strengths and weaknesses of the study}

The quality and consistency of frailty coding may have varied across practices reducing accuracy in identifying frailty and aspects of management. Many, if not most, practices may have used the electronic frailty index (EFI) ${ }^{19}$ a tool recommended by NHS England, to screen their patients for frailty based on information in the electronic patient record. Some practices may have 'batch'-coded frailty level based on the EFI, ${ }^{23}$ despite NHS England expressly stating that final diagnosis should be validated clinically. ${ }^{78}$ We cannot demonstrate how reliable the registered coding is and we could not find a precise way to identify 'batch coding' practices. ${ }^{23}$ It is possible that we lacked some key explanatory measures, even though we analysed commonly used indicators of healthcare demand and supply. We kept all variables in the analysis and relied on stepwise regression to remove the most colinear and identify the subset with the greatest explanatory power. We categorised continuous explanatory factors: exploratory analysis indicated a high number of non-linear relationships to outcomes and categorisation facilitated presentation of results as marginal means, which in our view made interpretation easier. Outcomes may have deviated from a true negative binomial distribution and to account for this, we used a robust estimator of variance for significance testing and CI construction.

\section{Implication for clinicians and policymakers}

Although the results demonstrated some associations that might be expected-such as higher rates of frailty coding at practices with higher chronic caseloads-other associations were counterintuitive: most notably lower assessment and prevalence rates at practices with greater representation of older patients. Thus, we do not believe the contract data currently provide a good proxy for actual prevalence. Our results suggest that targeting has led to practices assessing and coding principally severely frail individuals they may already know and be managing appropriately, and conversely to 'miss' the majority of moderately frail patients-those whom evidence suggests can benefit most from early interventions. ${ }^{24}{ }^{25}$

Targeted screening may be a sensible pragmatic approach in a busy, overstretched, clinical environment. In a parallel study, we undertook in-depth interviews with staff at a number of practices, ${ }^{12}$ and many had developed a bespoke targeting strategy to implement the contractual requirements. Many also expressed concern about insufficient capacity in local services to manage all of the identified needs following the frailty assessments; professionals did not want to be in a sensitive position of just screening and classifying older adults as frail if they were unable to provide appropriate interventions. ${ }^{12} 26$

Notwithstanding such concerns, the evidence of this study suggests that CCGs are important drivers of practicelevel implementation. CCGs may share the same concerns about the availability of suitable interventions and meeting increased levels of demand, but have ultimate responsibility for commissioning the necessary services.
Hence, making further progress on implementation at the practice level may depend very much on achieving greater engagement of CCGs themselves, particularly in the commissioning of suitable interventions.

\section{Comparison of our findings with other studies}

The frailty contractual requirements are new, with limited published data on factors associated with successful implementation. The previous year's contract data reveal that $9.5 \%$ were coded as moderately or severely frail in 2017/2018 ${ }^{27}$ : nearly double the rate for 2018/2019, suggesting that the earlier figure may have been inflated by batch-coding that was largely abandoned after NHS England expressed concerns. Falls assessments were introduced in 2018/2019 but only 3.7\% of frail patients were reported to have received some form of falls assessment, despite an estimated annual falls rate of $30 \%$ in those $65+$ years. ${ }^{28}$ Barriers to implementing falls interventions reported by GPs include insufficient time and doubt about the effectiveness of fall interventions, ${ }^{29}$ despite evidence that these can be effective. ${ }^{30}$ Medication reviews for the severely frail seem a complicated area that may need more guidance, ${ }^{31}$ due to their multimorbidity, polypharmacy and limited life expectancy. ${ }^{31} 32$

\section{CONCLUSION}

CCG membership appears to be the strongest determinant of GP practice engagement with the frailty contract, and fuller implementation at the practice level may depend on greater engagement of CCGs themselves, particularly in commissioning suitable interventions. Practices understandably targeted frailty assessments at patients likely to be severely frail, which can have resulted in underidentification of moderately frail individuals who might benefit most from early interventions. Frailty prevalence estimates based on the contract data may not accurately reflect actual rates.

\section{Twitter Khulud Alharbi @CarePrimary}

Collaborators This research was supported by the National Institute for Health Research (NIHR) Applied Research Collaboration Kent, Surrey, Sussex.

Contributors The idea for this article originated from an ongoing $\mathrm{PhD}$ research programme around patient frailty in UK primary care (KA). DR, KA, TB and HvM conceived of the article. DR and KA developed the statistical analysis plan and KA performed the analysis under the supervision of DR. KA wrote the manuscript with contributions and comments from DR, HvM and TB. DR is guarantor of the article.

Funding This is a doctoral-funded study through Umm Al-Qura University to the University of Manchester. This paper is linked to independent research funded by the National Institute for Health Research School for Primary Care Research.

Disclaimer The views expressed in this document are those of the authors and not necessarily those of the NHS, NIHR or the Department of Health and Social Care.

Competing interests None declared.

Patient consent for publication Not required.

Ethics approval This study used only publicly available data and ethics approval was not required.

Provenance and peer review Not commissioned; externally peer reviewed. 
Data availability statement No data are available. No additional data are available. All data used in this study are freely and publically available online. The relevant sources including URLs are provided in the online supplemental table 3.

Supplemental material This content has been supplied by the author(s). It has not been vetted by BMJ Publishing Group Limited (BMJ) and may not have been peer-reviewed. Any opinions or recommendations discussed are solely those of the author(s) and are not endorsed by BMJ. BMJ disclaims all liability and responsibility arising from any reliance placed on the content. Where the content includes any translated material, BMJ does not warrant the accuracy and reliability of the translations (including but not limited to local regulations, clinical guidelines, terminology, drug names and drug dosages), and is not responsible for any error and/or omissions arising from translation and adaptation or otherwise.

Open access This is an open access article distributed in accordance with the Creative Commons Attribution Non Commercial (CC BY-NC 4.0) license, which permits others to distribute, remix, adapt, build upon this work non-commercially, and license their derivative works on different terms, provided the original work is properly cited, appropriate credit is given, any changes made indicated, and the use is non-commercial. See: http://creativecommons.org/licenses/by-nc/4.0/.

\section{ORCID iDs}

Khulud Alharbi http://orcid.org/0000-0001-6245-7880

Harm van Marwijk http://orcid.org/0000-0001-6206-485X

David Reeves http://orcid.org/0000-0001-6377-6859

\section{REFERENCES}

1 Moody DNE, Lyndon HNE, GNK DS. Toolkit for general practice in supporting older people living with frailty, 2017. Available: https:// www.england.nhs.uk/publication/toolkit-for-general-practice-insupporting-older-people-living-with-frailty/

2 Di Pollina L, Guessous I, Petoud V, et al. Integrated care at home reduces unnecessary hospitalizations of community-dwelling frail older adults: a prospective controlled trial. BMC Geriatr 2017;17:53.

3 Gale CR, Cooper C, Aihie Sayer A, ihi SAA. Prevalence of frailty and disability: findings from the english longitudinal study of ageing. Age Ageing 2015;44:162-5.

4 Xue Q-L. The frailty syndrome: definition and natural history. Clin Geriatr Med 2011;27:1-15 http://www.ncbi.nlm.nih.gov/pmc/articles/ PMC3028599/

5 Puts MTE, Toubasi S, Andrew MK, et al. Interventions to prevent or reduce the level of frailty in community-dwelling older adults: a scoping review of the literature and international policies. Age Ageing $2017 ; 31$.

6 Tarazona-Santabalbina FJ, Gómez-Cabrera MC, Pérez-Ros P, et al. A multicomponent exercise intervention that reverses frailty and improves cognition, emotion, and social networking in the community-dwelling frail elderly: a randomized clinical trial. J Am Med Dir Assoc 2016;17:426-33.

7 England NHS, Reader I. Supporting routine frailty identification and frailty through the GP contract 2017/2018, 2018. Available: https://www.england.nhs.uk/publication/supporting-routine-frailtyidentification-and-frailty-through-the-gp-contract-20172018/

8 NHS Employers. Identification and management of patients with frailty summary of requirements, 2017. Available: http://www. nhsemployers.org/ /media/Employers/Documents/Primary care contracts/GMS/Summary of requirements for frailty.pdf

9 Robinson F. Clinical commissioning: GPs in charge? , 2016: 2, 10-11. https://www.kingsfund.org.uk/sites/default/files/field/field publication_file/Clinical_commissioning_web_pdf.pdf

10 Our work on CCGs - clinically-led bodies responsible for planning local health and care servicesKings fund [Internet]. Available: https:// www.kingsfund.org.uk/topics/clinical-commissioning-groups

11 NHS England. Enhanced service specification, 2015. Available: https://www.england.nhs.uk/commissioning/wp-content/uploads/ sites/12/2015/03/avoid-unplanned-admissions-03-15.pdf
12 Alharbi K, Van MH, Reeves D. Identification and management of frailty in english primary care : a qualitative study of national policy. BJGP Open 2020:1-12.

13 Reeves D, Pye S, Ashcroft DM, et al. The challenge of ageing populations and patient frailty: can primary care adapt? BMJ 2018;362:k3349 http://dx.doi.org/10.1136/bmj.k3349

14 GP contract services 2018-19. Available: https://digital.nhs.uk/dataand-information/publications/statistical/gp-contract-services/201819/gpprac1819

15 Quality and outcomes framework, achievement, prevalence and exceptions data - 2017-18 [PAS]. Available: https://digital.nhs. uk/data-and-information/publications/statistical/quality-andoutcomes-framework-achievement-prevalence-and-exceptionsdata/2017-18

16 Department for Communities and Local Government. English indices of deprivation 2015; 2015: 1-38. https://www.gov.uk/government/ statistics/english-indices-of-deprivation-2015

17 StataCorp LLC. Section 20.22 obtaining robust variance estimates. In: Stata User's Guide. 16 edn. College Station, TX: StataCorp, 2019: 288-92.

18 Zheng B, Agresti A. Summarizing the predictive power of a generalized linear model. Stat Med 2000;19:1771-81.

19 Clegg A, Bates C, Young J, et al. Development and validation of an electronic frailty index using routine primary care electronic health record data. Age Ageing 2016;45:353-60.

20 National Audit Office. A review of the role and costs of clinical commissioning groups, 2018. Available: http://www.sciesocialcareonline.org.uk/a-review-of-the-role-and-costs-of-clinicalcommissioning-groups/r/a110f00000NYOPhAAL

21 Weald H, Havens L. Frailty strategy 2017 - 2020 2018;11:1-18.

22 ICOPE. Integrated care for older people in Worcestershire, 2018. Available: https://worcestershire.moderngov.co.uk/documents/ s20296/9a\%20Final\%20ICOPE\%20Strategy_Oct\%202018_V3.pdf

23 Record SC, Employers NHS, England NHS. GMS Contract requirements for the identification and management of people with frailty - guidance on batch-coding; 2017: 1-2. https://www.england. nhs.uk/wp-content/uploads/2017/04/gms-contract-batch-codingstatement.pdf

24 Binder EF, Schechtman KB, Ehsani AA, et al. Effects of exercise training on frailty in community-dwelling older adults: results of a randomized, controlled trial. J Am Geriatr Soc 2002;50:1921-8.

25 Gill TM, Baker DI, Gottschalk M, et al. A program to prevent functional decline in physically frail, elderly persons who live at home. N Engl J Med Overseas Ed 2002;347:1068-74.

26 Gwyther H, Shaw R, Jaime Dauden E-A, et al. Understanding frailty: a qualitative study of European healthcare policy-makers' approaches to frailty screening and management. BMJ Open 2018;8:e018653.

27 Cumbria N, Care T, Network H. Regional frailty community of practice, 2018. Available: http://frailtyicare.org.uk/wp-content/ uploads/2018/09/NENC-Draft-Frailty-Tool-V-30.8.18-003.docx-finalSep-4th-version-002.pdf

28 NICE. Guidance and guidelines. In: Falls in older people: assessing risk and prevention, 2013. https://www.nice.org.uk/guidance/cg161/ resources/falls-in-older-people-assessing-risk-and-prevention35109686728645

29 Mackenzie L, Mclntyre A. How do general practitioners (GPs) engage in falls prevention with older people? a pilot survey of GPs in NHS England suggests a gap in routine practice to address falls prevention. Front Public Health 2019;7:1-10.

30 Phelan EA, Mahoney JE, Voit JC, et al. Assessment and management of fall risk in primary care settings. Med Clin North Am 2015;99:281-93.

31 Khera S, Abbasi M, Dabravolskaj J, et al. Appropriateness of medications in older adults living with frailty: impact of a pharmacistled structured medication review process in primary care. J Prim Care Community Health 2019;10:215013271989022.

32 Poudel A, Hubbard RE, Nissen L, et al. Frailty: a key indicator to minimize inappropriate medication in older people. QJM 2013;106:969-75. 